Ethnic density and risk of mental ill health - The case of religious sectarianism in Northern Ireland : A population data linkage study

Bosqui, Tania

2017-07

Bosqui , T , Maguire , A , Kouvonen , A M , Wright , D , Donnelly , M \& O'Reilly , D 2017 , ' Ethnic density and risk of mental ill health - The case of religious sectarianism in Northern Ireland : A population data linkage study ' , Health \& Place , vol. 47 , pp. 29 . https://doi.org/10.1016/j.healthplace.20

http://hdl.handle.net/10138/305113

https://doi.org/10.1016/j.healthplace.2017.06.010

cc_by_nc_nd

acceptedVersion

Downloaded from Helda, University of Helsinki institutional repository.

This is an electronic reprint of the original article.

This reprint may differ from the original in pagination and typographic detail.

Please cite the original version. 


\section{Ethnic density and risk of mental ill health - the case of religious sectarianism in Northern Ireland: A population data linkage study}

Tania J. Bosqui

Corresponding Author

Administrative Data Research Centre - Northern Ireland (ADRC- NI), Centre for Public Health, Queen's University Belfast, Royal Victoria Hospital, Grosvenor Road, Belfast BT 12 6BA, t.bosqui@qub.ac.uk

\section{Aideen Maguire}

UKCRC Centre of Excellence for Public Health (Northern Ireland), Centre for Public Health, Queen's University Belfast, Royal Victoria Hospital, Grosvenor Road, Belfast BT 12 6BA, a.maguire@qub.ac.uk

\section{Anne Kouvonen}

Department of Social Research, University of Helsinki, Unioninkatu 37, Helsinki, Finland, anne.kouvonen@helsinki.fi University of Social Sciences and Humanities, Faculty in Wroclaw, Wroclaw, Poland UKCRC Centre of Excellence for Public Health (Northern Ireland), Queen's University Belfast, Belfast, UK

\section{David Wright}

Administrative Data Research Centre - Northern Ireland (ADRC- NI), Centre for Public Health, Queen's University Belfast, Royal Victoria Hospital, Grosvenor Road, Belfast BT 12 6BA, d.wright@qub.ac.uk

Michael Donnelly

Administrative Data Research Centre - Northern Ireland (ADRC- NI) and the UKCRC Centre of Excellence for Public Health (Northern Ireland) , Centre for Public Health, Queen's University Belfast, Royal Victoria Hospital, Grosvenor Road, Belfast BT 12 6BA, michael.donnelly@qub.ac.uk

\section{Dermot O’Reilly}

Administrative Data Research Centre - Northern Ireland (ADRC- NI) and the UKCRC Centre of Excellence for Public Health (Northern Ireland) , Centre for Public Health, Queen's University Belfast, Royal Victoria Hospital, Grosvenor Road, Belfast BT 12 6BA, d.oreilly@qub.ac.uk 
Ethnic density and risk of mental ill health - the case of religious sectarianism in Northern Ireland:

\section{A population data linkage study}

\section{ABSTRACT}

An ethnic group that lives in a neighbourhood in which it is in the minority, termed 'lower ethnic density, tends to report a higher incidence of mental ill-health. This population-based study investigated for the first time the existence of an own-group density effect among Catholic and Protestant communities in Northern Ireland. The entire Northern Ireland born Catholic and Protestant working age $(n=1,004,060)$ enumerated population in the 2011 Census of Northern Ireland were included in the study via administrative data-linkage methodology. Catholics had a greater likelihood of reporting mental ill health in neighbourhoods with the largest proportion of Catholics (OR=1.25, 95\% Cl 1.07-1.47), whereas mental health among Protestants was not associated with neighbourhood proportion of Protestants, after adjusting for socio-economic status and neighbourhood deprivation. The results indicate that a complex relationship exists between group identity, population composition of ethnic and religious groups and prevalence of community mental health.

\section{Keywords}

Ethnicity; mental health; religion; neighbourhood; Northern Ireland

\section{INTRODUCTION}

Elevated psychiatric morbidity has been found across ethnic minority groups [1, 2]. Theories that minority ethnic groups tend to be more vulnerable to social exclusion, unemployment and insecure housing, all of which have been associated with risk for mental ill health [3], or that such groups have been victim to institutional racism in diagnosis and access to preventative interventions [4], have been insufficient in fully explaining the complexity of this increased risk [5]. Considering neighbourhood effects has provided further insight; ethnic minority individuals have an increased incidence of mental health difficulties, compared to the rest of the population, when living in a neighbourhood in which their own group is a minority and a relative decrease in incidence when their group is in the majority, regardless of individual or neighbourhood deprivation $[6,7]$. This has been termed the ethnic density effect. 
Mechanisms to explain this phenomenon include exposure to racism, which is directly linked to increased mental health difficulties [8] and more likely to occur in low ethnic density areas [9]; poorer access to appropriate and accessible services [10]; and lower social capital, greater social isolation and greater social marginalisation [11]. If the effect is related to the experience of being a minority then it would be reasonable to conclude that this effect would also be found within other types of minority groups. Indeed, some studies have found an effect for French speaking residents in Canada [12] and for single parents [13].

Studying the neighbourhood density effect in Northern Ireland offers a unique opportunity, given that the population of Northern Ireland is made up of a large minority ( $45.14 \%$ Catholic) and small majority (48.36\% Protestant [14]). Religious affiliation is of ongoing social importance since the official end of the civil conflict known as 'The Troubles' with the signing of the Good Friday Agreement in 1998. The Troubles led to the violent deaths of over 3,500 people, in a population of approximately 1.5 million; with many more injured or psychologically traumatised [15]. Christian religious denomination has become amalgamated with a polarisation of complex cultural, ethnic and political affiliation associated with predominantly Catholic nationalism or Protestant unionism. Sectarian motivated prejudice and discrimination manifests itself through distinctions made using names, accents, or place of birth [16, 17]. Although the two groups are clearly not homogenous [18], the Catholic and Protestant polarisation has become evident in the religious segregation of neighbourhoods across Northern Ireland [19]. Neighbourhoods in Northern Ireland can be highly concentrated by religion with up to $98 \%$ of the population belonging to the dominant group, with territories marked through flags, murals and overt political affiliations. The segregation of neighbourhoods has increased over time since the early 1970s, particularly during the Troubles, due to the migration of people to own-group areas in search of safety [20]. Today, around $40 \%$ of the population live in these highly divided neighbourhoods, which also tend to have relatively high rates of income deprivation. There are over 80 interface barriers separating highly Protestant and highly Catholic neighbourhoods, including walls, barriers and gates. They are located across Northern Ireland, predominantly in the largest urban conurbations of Belfast and Derry, and their continuing existence reflects the ongoing tension between adjacent communities [21]. Still, a substantial proportion of neighbourhoods in Northern Ireland are well mixed between the two dominant groups. Northern Ireland therefore provides a comprehensive range of population densities for research purposes.

This study therefore aims to establish if a neighbourhood own-group density effect exists for both Catholic and Protestant affiliated populations on the prevalence of mental health conditions, 
measured as self-reported mental health from the 2011 Census of Northern Ireland. Given past research on the protective effect of own-group ethnic density for ethnic minorities, this study hypothesises that a) a protective own-group density effect will exist for both Catholics and Protestants respectively, and b) the effect will not be entirely explained by socio-economic disadvantage.

\section{METHOD}

\section{Data}

Data linkage methodology was used as part of the Northern Ireland Mortality Study (NIMS) which holds data on the entire population of Northern Ireland enumerated in the 2011 Census ( $n=1.811$ million). Data for this study was therefore derived from working age residents of Northern Ireland who responded to the 2011 Census, and linked to publicly available neighbourhood data held by the Northern Ireland Neighbourhood Information Service (NINIS). Census and Neighbourhood datasets were linked using anonymous one-way encryption methods by the data custodians at the Northern Ireland Statistics and Research Agency (NISRA), and the anonymous data was made available to the research team. After analysis, final output was screened by the Northern Ireland Longitudinal Study (NILS) Research Support Officers for non-identifiability and approved final output released for publication. Ethical approval was obtained from both the School of Medicine, Dentistry and Biomedical Sciences, Queen's University Belfast, and NISRA, who conform to the principles embodied in the Declaration of Helsinki.

Prior to analysis, those aged less than 18 years old $(n=405,123)$, more than 75 years old ( $n=105,149)$, living in an institution $(n=10,791)$ or with imputed data for age, sex or mental health $(n=44,232)$ were excluded. Remaining individuals who self-reported as 'no religion' $(n=50,539)$ or 'other religion' $(n=11,615)$ were also excluded, as well as those remaining who were not born in Northern Ireland $(n=123,513)$. This was predominantly people born in the rest of the United Kingdom or the Republic of Ireland (approximately 67.43\%). Any non-response (missing) data was included as a separate category. The number of non-responses varied by Census question, and was only present for home ownership ( $n=76,291,7.60 \%)$ and settlement band $(n=18,342,1.83 \%)$.

\section{Variables}


Socio-demographic variables

Variables derived from the Census were age, gender, religion, country of birth, marital status, and socio-economic status which included qualifications, housing tenure, housing value, and car ownership. Religion ('Catholic' vs. 'Protestant/Christian other including Christian-related') was an amalgamation of two Census questions, where if an individual did not report their religion 'brought up in' then their response to their religion 'belonging to' was used. Country of birth was grouped into those born in Northern Ireland, those born outside of Northern Ireland and those for whom the question was not required, such as students. Qualifications include GCSEs and A-levels, referring to the United Kingdom examinations at the end of secondary school (age 14-16) and high school (age 1618) respectively. Housing tenure and value were grouped, where a value was assigned to those who own their property outright, with a mortgage or part-owned. The renting variable included those renting with or without housing benefit, or who are living rent-free. Housing value was derived from capital values not exempt from local taxation in 2005. Exemptions include properties that are second homes, empty or student housing. A variable for movement between neighbourhoods in the last 12 months was created using the Census question on current and past addresses, which included a category for term-time movement of students.

\section{Area-level measures}

Data from the Census were linked to publicly available neighbourhood data held by NINIS to determine religious neighbourhood density and area deprivation. For density, data were linked using the 4,537 Census Small Area codes which have a mean size of 399 people $(S D=202.97)$ per neighbourhood. Small Areas were sorted and converted into deciles from low to high religious density using religion 'brought up in' and calculated separately for Catholic and for Protestant. For area deprivation, data were linked using the 890 Super Output Area codes which have a mean of 2,035 residents ( $S D=547.28)$ using an Income Domain Score created in 2010, which was converted into quintiles from high to low area income deprivation [22]. The score is derived by identifying the proportion of individuals on incomerelated benefits and tax credits in each Small Area. Due to data anonymity rules, Census Small Area codes were not obtainable at the individual level and could not be used in a multi-level analysis. Super Output Area identifiers were therefore used instead in a multi-level model to adjust for any unobserved neighbourhood effects.

Outcome measure 
A dichotomous self-reported mental health status was derived from a census question which asks whether the individual has had 'an emotional, psychological or mental health condition (such as depression or schizophrenia)' which has lasted, or is expected to last, at least 12 months.'

\section{Statistical analysis}

Three multi-level logistic regression models were run. The first multi-level model was unadjusted and included only individual religion and neighbourhood density based on religion. The second multi-level model was adjusted for individual socio-economic characteristics (sex, age, marital status, highest qualification, housing tenure and car ownership). The final fully adjusted multi-level model adjusted for both individual and neighbourhood socio-economic characteristics (sex, age, marital status, highest qualification, housing tenure, car ownership, change of address in the last 12 months, urban rural settlement band and area deprivation). All models included non-response (missing) data as a separate category. Post hoc analyses were conducted using likelihood ratio tests. Data was analysed using STATA 13 in the NILS secure environment.

\section{RESULTS}

The overall Northern Ireland born Catholic and Protestant community sample totalled 1,004,060 working age adults (age range 18-75; male $=48.32 \%$ and female $=51.68 \%$; Catholic $=45.35 \%$ and Protestant $=54.65 \%)$. Table 1 shows socio-demographic characteristics of the sample categorised by self-reported religion. Catholics tended to be younger, living in rented accommodation and resident in deprived areas compared to the Protestant population ( $p<.001$ in all $X^{2}$ tests). Missing data was low (9.43\% of the total sample had missing housing tenure or settlement band) and was evenly spread between Catholics and Protestants.

Table 1

Socio-demographic characteristics of Catholic and Protestant/Christian Other working age adults

\begin{tabular}{llllll}
\hline Socio-demographic characteristic & Catholic & \multicolumn{3}{c}{ Protestant/Christian Other } \\
& & $n$ & $\%$ & $n$ & $\%$ \\
\hline Sex & Male & & & & \\
& Female & 218,491 & 47.98 & 266,710 & 48.61 \\
Age & 236,875 & 52.02 & 281,984 & 51.39 \\
& $18-34$ & & & & \\
& $35-49$ & 159,028 & 34.92 & 148,684 & 27.10 \\
& $50-64$ & 138,482 & 30.41 & 162,496 & 29.62 \\
& $65-75$ & 110,377 & 24.24 & 151,073 & 27.53 \\
\hline
\end{tabular}




\begin{tabular}{|c|c|c|c|c|}
\hline \multicolumn{5}{|l|}{ Marital status } \\
\hline Married or civil partnership & 217,856 & 47.84 & 304,601 & 55.51 \\
\hline Cohabiting & 24,631 & 5.41 & 31,904 & 5.81 \\
\hline Single & 158,473 & 34.80 & 142,120 & 25.90 \\
\hline Separated & 20,025 & 4.40 & 18,324 & 3.34 \\
\hline Divorced or dissolved civil partnership & 19,308 & 4.24 & 30,246 & 5.51 \\
\hline Widowed including civil partnership & 15,073 & 3.31 & 21,498 & 3.92 \\
\hline \multicolumn{5}{|l|}{ Highest qualification } \\
\hline None & 123,940 & 27.22 & 144,742 & 26.38 \\
\hline GCSEs 1-4 & 73,595 & 16.16 & 95,867 & 17.47 \\
\hline GCSEs 5+ & 67,529 & 14.83 & 84,601 & 15.42 \\
\hline A-levels & 61,850 & 13.58 & 71,777 & 13.08 \\
\hline Degree or higher & 116,759 & 25.64 & 134,081 & 24.44 \\
\hline Other & 11,693 & 2.57 & 17,626 & 3.21 \\
\hline \multicolumn{5}{|l|}{ Housing tenure } \\
\hline$>£ 250,000$ & 17,602 & 3.87 & 30,601 & 5.58 \\
\hline$£ 200,000-249,999$ & 21,480 & 4.72 & 33,618 & 6.13 \\
\hline$£ 150,000-199,999$ & 53,450 & 11.74 & 73,952 & 13.48 \\
\hline$£ 100,000-149,999$ & 106,023 & 23.28 & 125,055 & 22.79 \\
\hline$£ 75,000-99,999$ & 69,168 & 15.19 & 71,640 & 13.06 \\
\hline$<£ 75,000$ & 37,203 & 8.17 & 55,574 & 10.13 \\
\hline Renting & 113,099 & 24.84 & 119,304 & 21.74 \\
\hline Non-response (missing) & 37,341 & 8.20 & 38,950 & 7.10 \\
\hline \multicolumn{5}{|l|}{ Car ownership } \\
\hline None & 70,707 & 15.53 & 65,127 & 11.87 \\
\hline $1 \mathrm{car}$ & 159,315 & 34.99 & 189,243 & 34.49 \\
\hline $2+$ cars & 225,344 & 49.49 & 294,324 & 53.64 \\
\hline \multicolumn{5}{|l|}{ Settlement band } \\
\hline Belfast (urban) & 119,579 & 26.26 & 199,963 & 36.44 \\
\hline Derry (urban) & 39,533 & 8.68 & 10,810 & 1.97 \\
\hline Intermediate & 148,340 & 32.58 & 179,448 & 32.70 \\
\hline Rural & 138,558 & 30.43 & 149,487 & 27.24 \\
\hline Non-response (missing) & 9,356 & 2.05 & 8,986 & 1.64 \\
\hline \multicolumn{5}{|l|}{ Area deprivation } \\
\hline Least deprived ( $1^{\text {st }}$ quintile) & 48,420 & 10.63 & 145,204 & 26.46 \\
\hline Intermediate $\left(2^{\text {nd }}-4^{\text {th }}\right.$ quintile $)$ & 281,992 & 61.93 & 340,209 & 62.01 \\
\hline Most deprived ( $5^{\text {th }}$ quintile) & 124,954 & 27.44 & 63,281 & 11.53 \\
\hline
\end{tabular}

The range of religious density in Northern Ireland was wide. In the $1^{\text {st }}$ decile for Catholic population density, the proportion of Catholics is under $5.54 \%$ of the neighbourhood population; whilst in the $10^{\text {th }}$ decile over $92.38 \%$ of the neighbourhood is Catholic. For Protestant density, the proportion of Protestants in the $1^{\text {st }}$ decile is under $5.45 \%$; whilst in the $10^{\text {th }}$ decile it is over $85.67 \%$. The highest Catholic density neighbourhoods are also the most highly deprived and are more urban than low Catholic density neighbourhoods ( $p<.001$ in all $X^{2}$ tests). Conversely, the lowest density Protestant neighbourhoods are the most deprived and more urban than high Protestant density neighbourhoods $\left(p<.001\right.$ in all $X^{2}$ tests). For more detail on neighbourhood characteristics see Supplementary Table 1. 
Census Small Areas, which were used to calculate deciles, are displayed in map form in Figure 1. This shows the geographical breadth and mix of neighbourhood composition across Northern Ireland. As linked Census Small Area data was not obtainable through NIMS, data is derived directly from NINIS [23]. Copyright permission was granted by the Ordnance Survey Land Registry Directorate.

Figure 1

Percentage of Catholics in each Census Small Area using religion or religion brought up in according to the 2011 Northern Ireland Census [23]

(Insert Figure 1).

The prevalence of self-reported mental health conditions was $7.80 \%$, and was higher for Catholics (8.69\%) than Protestants $\left(7.06 \%, X^{2}(1, n=1,004,060)=921.68, p<.001\right)$. Self-reported mental health conditions were higher for females, those aged 50-64, divorced or separated, no qualifications, renting, living in urban and deprived areas, and in low Protestant density areas and high Catholic density areas ( $p<.001$ in all $X^{2}$ tests). For more detail of socio-demographic and geographic differences between those reporting and not reporting a mental health condition see Supplementary Table 2.

Table 2 displays the multi-level logistic regressions for self-reported mental health and own-group religious neighbourhood density. The fully adjusted multi-level model shows that Catholics living in areas with the greatest proportion of Catholics had a $25 \%$ greater likelihood of reporting mental health difficulties compared to those in areas with the smallest proportion (OR=1.25, 95\% Cl 1.07-1.47). The model shows a two-way split where individuals in the four deciles with the highest proportion of Catholics have a significantly higher likelihood of mental health difficulties than those in the lowest decile. Likelihood of mental health difficulties was similar across deciles 1-6 (which signify a Catholic density of $\leq 5.54 \%$ up to $48.37 \%)$.

A different picture emerges for the Protestant population. The unadjusted multi-level model clearly shows a decrease in the likelihood of self-reported mental health difficulties of Protestants as the density of the Protestant population increases, with Protestants living in the most densely Protestant areas $33 \%$ less likely to report poor mental health compared to Protestants living in the least densely Protestant areas $(\mathrm{OR}=0.67,95 \% \mathrm{Cl} 0.58-0.76)$. However, this association disappeared in the fully adjusted multi-level model with no significant differences among deciles in the likelihood of mental health difficulties, indicating that socioeconomic factors explain this protective effect. These findings, 
for both Catholics and Protestants, are represented visually in Figure 2, where the left hand panels present the distribution of the population between religious density deciles, stratified by Catholic (top panel) and Protestant (bottom panel) populations. The overall number of individuals in each decile is shown by the total area of the bars (length* width) and density figures on the $y$ axis represent the area level population. The right hand panel presents the corresponding estimated probability (Odds Ratios) of poor mental health for each decile by religion.

Table 2

Likelihood of self-reported mental health conditions by neighbourhood religious density, stratified by religion 


\begin{tabular}{|c|c|c|c|c|c|c|}
\hline & \multicolumn{2}{|l|}{ Model 1} & \multicolumn{2}{|c|}{ Partially adjusted model $2^{a}$} & \multicolumn{2}{|c|}{ Fully adjusted model $3^{b}$} \\
\hline & Odds ratio & $95 \% \mathrm{Cl}$ & Odds ratio & $95 \% \mathrm{Cl}$ & Odds ratio & $95 \% \mathrm{Cl}$ \\
\hline \multicolumn{7}{|c|}{ Catholic population, $n=455,366$} \\
\hline \multicolumn{7}{|c|}{$(39,570$ with self-reported mental health conditions) } \\
\hline \multicolumn{7}{|c|}{ Catholic neighbourhood density ${ }^{c}$} \\
\hline 1st decile: Least dense & 1.00 & & 1.00 & & 1.00 & \\
\hline $2^{\text {nd }}$ & 1.01 & $0.84-1.23$ & 1.04 & $0.86-1.26$ & 1.05 & $0.87-1.27$ \\
\hline $3^{\text {rd }}$ & 1.00 & $0.83-1.21$ & 1.18 & $0.99-1.41$ & 1.19 & $0.90-1.42$ \\
\hline $4^{\text {th }}$ & 0.93 & $0.78-1.12$ & 1.07 & $0.90-1.35$ & 1.07 & $0.90-1.42$ \\
\hline $5^{\text {th }}$ & 1.00 & $0.84-1.19$ & 1.12 & $0.95-1.32$ & 1.13 & $0.96-1.33$ \\
\hline $6^{\text {th }}$ & 1.04 & $0.88-1.24$ & 1.15 & $0.97-1.35$ & 1.15 & $0.98-1.35$ \\
\hline $7^{\text {th }}$ & 1.06 & $089-1.26$ & 1.18 & $1.01-1.38^{*}$ & 1.18 & $1.01-1.38 *$ \\
\hline $8^{\text {th }}$ & 1.20 & $1.02-1.43^{*}$ & 1.24 & $1.06-1.45^{* *}$ & 1.22 & $1.06-1.46^{*}$ \\
\hline $9^{\text {th }}$ & 1.37 & $1.15-1.62 * * *$ & 1.31 & $1.12-1.53 * *$ & 1.25 & $1.06-1.46^{* *}$ \\
\hline 10th decile: Most dense & 1.35 & $1.14-1.60 * *$ & 1.33 & $1.13-1.55^{* * *}$ & 1.25 & $1.07-1.47^{* *}$ \\
\hline \multicolumn{7}{|c|}{ Protestant population, $n=548,694$} \\
\hline \multicolumn{7}{|c|}{$(38,726$ with self-reported mental health conditions) } \\
\hline \multicolumn{7}{|c|}{ Protestant neighbourhood density ${ }^{c}$} \\
\hline 1st decile: Least dense & 1.00 & & 1.00 & & 1.00 & \\
\hline $2^{\text {nd }}$ & 0.92 & $0.80-1.07$ & 0.98 & $0.85-1.12$ & 0.99 & $0.87-1.14$ \\
\hline $3^{\text {rd }}$ & 0.76 & $0.66-0.87 * * *$ & 0.96 & $0.85-1.09$ & 1.00 & $0.88-1.14$ \\
\hline $4^{\text {th }}$ & 0.70 & $0.61-0.80 * * *$ & 0.90 & $0.80-1.02$ & 0.95 & $0.84-1.08$ \\
\hline $5^{\text {th }}$ & 0.66 & $0.58-0.76 * * *$ & 0.86 & $0.76-0.98^{*}$ & 0.91 & $0.80-1.03$ \\
\hline $6^{\text {th }}$ & 0.70 & $0.61-0.80 * * *$ & 0.86 & $0.76-0.97^{*}$ & 0.91 & $0.80-1.03$ \\
\hline $7^{\text {th }}$ & 0.68 & $0.60-0.80 * * *$ & 0.84 & $0.75-0.96 * *$ & 0.89 & $0.79-1.01$ \\
\hline $8^{\text {th }}$ & 0.69 & $0.61-0.80 * * *$ & 0.86 & $0.76-0.97^{*}$ & 0.91 & $0.80-1.03$ \\
\hline $9^{\text {th }}$ & 0.71 & $0.62-0.82 * * *$ & 0.87 & $0.77-0.98 *$ & 0.93 & $0.82-1.05$ \\
\hline 10th decile: Most dense & 0.67 & $0.58-0.76 * * *$ & 0.83 & $0.74-0.94 * *$ & 0.89 & $0.78-1.00$ \\
\hline
\end{tabular}


${ }^{a}$ Multi-level model adjusted for individual socio-economic characteristics (sex, age, marital status, highest qualification, housing tenure and car ownership) and non-response (missing) data

${ }^{\mathrm{b}}$ Multi-level model adjusted for individual socio-economic characteristics, non-response (missing) data, change of address in the last 12 months and neighbourhood characteristics (settlement band and area deprivation)

c Population proportions (percentages) for small areas in each decile are given for each community background

$\mathrm{Cl}$, confidence interval

$* * P<0.05 ; * * P<0.01 ; * * * P<0.001$ 
Figure 2

Histograms indicating the distribution of the population (left-hand panels) and the estimated probability of poor mental health (right-hand panels), by religion.

(Insert Figure 2).

Post hoc testing was conducted to test interaction effects between a) religion and own-group density and b) own-group density and area deprivation. Interaction terms were introduced into the fully adjusted multi-level model for Catholics and Protestants combined and likelihood ratio tests conducted. In both cases, interaction effects were found, showing that the relationship between owngroup density and mental health was modified by religion $(X 2(17, n=1,004,060)=65.26, p<.001)$ and area deprivation $(X 2(47, n=1,004,060)=68.37, p<.05)$, indicating that the association between owngroup density and mental ill health was stronger for Catholics (e.g. highest own-group density area for Catholics $\mathrm{OR}=1.31,95 \% \mathrm{Cl}$ 1,12-1.53, for Protestants $\mathrm{OR}=1.06,95 \% \mathrm{Cl} .91-1.24)$ and in highly deprived areas (e.g. highest own-group density for high deprivation areas $\mathrm{OR}=1.15,95 \% \mathrm{Cl} 1.01-1.31$, for low deprivation areas $\mathrm{OR}=0.82,95 \% \mathrm{Cl} 0.62-1.08)$.

\section{DISCUSSION}

The findings showed that for the Catholic population of Northern Ireland, increasing Catholic population density has a detrimental effect on mental health, particularly in highly deprived areas. This effect increases the likelihood of mental ill health by $25 \%$ in the most dense own-group neighbourhoods compared to the least dense areas, after adjusting for socio-economic and neighbourhood characteristics. This is contrary to the study's hypothesis and expectations based on research on ethnic minorities $[1,24]$. In contrast, for the Protestant population, no effect was found either detrimental or protective.

Only two other studies reported an inverse relationship for the ethnic density effect in mental health; both found that Pakistani people in the United Kingdom had worse mental health in 'high ethnic density' neighbourhoods $[9,25]$. However, the studies defined 'own-group' in terms of ethnic minorities in general rather than, specifically, Pakistani people; and they may have been affected by prejudice and discrimination from other minority ethnic groups within the 'own-group' definition [24]. In a systematic review for an ethnic density effect in physical ill-health [26], contradictory findings 
have been found for Hispanic and African American populations, particularly for obesity. Own-group ethnic density was found to be protective for the Hispanic population but detrimental for the African American population. This was explained in terms of historical differences in prejudice, discrimination, neighbourhood segregation and poverty that may override any protective effects of high African American density neighbourhoods for African Americans, and which may create greater analytical difficulty in separating neighbourhood deprivation from population density effects [26]. Though a very different history from African Americans, the Catholic population of Northern Ireland has experienced centuries of oppression, discrimination and victimisation [27] and perhaps this created a complexity of deprivation in high density Catholic neighbourhoods that may not have been captured by a measure of area derivation that relied solely on income. This is supported by the post hoc analysis that showed the importance of high area deprivation in the relationship between density and mental ill health.

Aside from the role of historical oppression in area deprivation, it is also possible that Catholic and Protestant historical differences resulted in an actual harmful own-group density effect for the Catholic population. Catholic and Protestant identities in Northern Ireland are not homogenous, and have complex historical, ethnic and religious roots. In general terms however, in the Catholic case, there is a sense of injustice and victimisation after centuries of colonial oppression, with an ongoing desire for unity with the Republic of Ireland [27]; whilst in the Protestant case, there is a desire to remain as part of the United Kingdom and a sense of fear at the loss or dilution of Protestant cultural heritage after centuries of settler vulnerability and threat $[28,29]$. Individuals in high religious density neighbourhoods in Northern Ireland are likely to hold these identities more strongly $[30,31]$; indeed, the most densely populated areas by one or other religion have been also the most sectarian in terms of shared socio-political beliefs and externalised communal symbols such as flags and murals [32,33]. Social group status related to civil conflict [34] and to inferiority and victimisation has been shown to have devastating effects on mental health [35]. Given the group meanings in Northern Ireland, those living in high own-group density neighbourhoods may have a group dependant likelihood of developing mental ill health. The Protestant population, characterised by a siege mentality and vulnerability to loss of power to due to socio-political changes, may have a group identity that is protective, or at least not harmful, for their member's self-esteem and mental health. The Catholic population, however, whose identity is characterised by inequality and victimisation, may have a group identity that is more likely to be harmful for self-esteem and mental health.

In order to explore this hypothesis of a group dependant buffering effect, cross-comparisons with countries that have similar socio-political histories and neighbourhood structure, such as Lebanon 
[28], may help to identify a common pattern in group identities that are protective or harmful for mental health. Including a measure of individual meaning to group ownership, rather than assuming that own-group contact is by definition positive, could also improve such research. The effect of neighbourhood exposure to sectarianism could provide a further explanatory insight, given that exposure to racism has helped to explain similar findings for ethnic minority groups [e.g.9]. Furthermore, greater complexity in measuring area deprivation will help to separate deprivation from density effects.

\section{Strengths and limitations}

The present study has uncovered novel findings on minority status neighbourhood effects on selfreported mental ill health, using a high quality data linkage methodology with a large sample size and diversity in population densities. The validity of the study is also strengthened by the adjustment for a range of possible individual and neighbourhood contributing factors, including deprivation. Furthermore, in ethnic density studies, the high density neighbourhoods reach $45-65 \%$ own-group proportion [e.g.6] which is in stark contrast to this study in which these neighbourhoods reached over 95\%. In addition, Census data from one time point allowed adjustment for those who have moved into their neighbourhood less than one year previously. A common limitation of international research on neighbourhood effects is a lack of adjustment for the influence of temporal exposure to a neighbourhood [36].

A limitation of this study, however, is that it relies on self-reported mental health status. This can influence the prevalence of difficulties, particularly between Catholic and Protestant populations for whom state led information seeking can be interpreted very differently [37]. The definition of neighbourhood and of religion was also reliant on the Census definition and measurement, which may not reflect individual perceptions [38]. Furthermore, although this study was able to adjust for movement in the last year, linking Census data decade to decade would provide a greater longitudinal element to the analysis. This would be particularly useful given findings for neighbourhood deprivation effects which may be similar to density effects; the negative effect of living in a deprived neighbourhood weakens only after 3 years [36]. Furthermore, the spatial boundary characteristics of the neighbourhoods in this study were not considered but may be an important contributory factor in mental health. In a geographical analysis, some neighbourhood were found to be geographically adjacent but had very different population proportions [39]. It is plausible that those living in a high own-group density neighbourhood may be under greater social stress if that neighbourhood is 
immediately adjacent to a high other-group density neighbourhood. Finally, although missing data was relatively low and evenly spread between Catholics and Protestants, the results may have been affected by missing data for housing tenure and settlement band two key risk factors for mental ill health.

\section{Practical Implications}

The findings of this study contribute to neighbourhood mental health and minority population research by providing evidence for a novel additional underlying mechanism to those mechanisms already described in the ethnic density literature. Alongside access to social support, protection from prejudice and discrimination, and access to relevant resources and services; this study adds not only the meaning of an 'own-group' membership for an individual, but also that this may dictate whether own-group neighbourhood density increases are protective, neutral or harmful for mental health. This provides a new avenue of hypotheses with important implications for public mental health interventions. Firstly, the findings iterate that an individual's mental health can be strongly influenced by neighbourhood factors. As such, interventions aimed at improving mental health need to expand from individual one-to-one psychological or psychiatric interventions in order to encompass sociopolitical identity and neighbourhood dynamics. Secondly, the findings highlight the effect of neighbourhood density on mental health and raise questions about the benefits of greater own group contact, particularly for the Catholic population. Improving inter-group contact has been shown to lower anxiety and increase out-group empathy [40]. The current study highlights the continuing impact of sectarian identities on mental health, the particularly negative effect on Northern Ireland's Catholic population and the continuing need to improve cross-community contact.

\section{Conclusion}

In summary, this study demonstrates the complex relationship between individual and neighbourhood identity in Northern Ireland. The inverse relationship found for Catholic people raises questions about the simplicity of an ethnic density effect. The results show that own-group neighbourhood density can be harmful for some groups and this could be dependent on a range of individual, social, cultural and political factors. Further research is required to isolate these contributory factors to provide further insights. 


\section{ACKNOWLEDGEMENTS}

The help provided by the staff of the Northern Ireland Mortality Study (NIMS) and the NILS Research Support Unit is acknowledged. The NIMS is funded by the Health and Social Care Research and Development Division of the Public Health Agency (HSC R\&D Division) and NISRA. The NILS-RSU is funded by the ESRC and the Northern Ireland Government. The authors alone are responsible for the interpretation of the data and any views or opinions presented are solely those of the author and do not necessarily represent those of NISRA/NILS.

\section{REFERENCES}

1 Shaw RJ, Atkin K, Bécares L, Albor CB, Stafford M, Kiernan KE, Nazroo JY, Wilkinson RG, Pickett KE. Impact of ethnic density on adult mental disorders: Narrative review. Br J Psychiatry 2012;201:11-19.

2 Neeleman J, Wilson-Jones C, Wessely S. Ethnic density and deliberate self harm; A small area study in south east London. J Epidemiol Community Health, 2001;55:85-90.

3 Muntaner C, Ng E, Chung H, et al. Mental health. In: Levy B, Sidel VW, editors. Social injustice and public health. Oxford: Oxford University Press 2013. p.272-288.

4 Morgan C, Hutchinson G. The social determinants of psychosis in migrant and ethnic minority populations: A public health tragedy. Psychol Med 2010;40:705-709.

5 Brown JS, Meadows SO, Elder GH. Race-ethnic inequality and psychological distress: depressive symptoms from adolescence to young adulthood. Dev Psychol 2007;43: 1295-311.

6 Schofield P, Ashford M, Jones R. Ethnic isolation and psychosis: re-examining the ethnic density effect. Psychol Med 2010;41:1263-1269.

7 McKenzie K, Serfaty M, Crawford M. Suicide in ethnic minority groups. Br J Psychiatry, 2003;183:100101.

8 Williams DR, Williams-Morris R. Racism and mental health: The African American experience. Ethnicity \& Health, 2010;5:243-268.

9 Bécares L, Nazroo J, Stafford M. The buffering effects of ethnic density on experienced racism and health. Health Place 2009;15:700-708.

10 Whitley R, McKenzie K, Stewart R. Exploring the ethnic density effect: A qualitative study of a London ward. Int J Soc Psychiatry, 2006;52:376-391. 
11 Kirkbride J, Morgan C, Fearon P, Dazzan P, Murray RM, Jones PB. Neighbourhood-level effects on psychoses: Re-examining the role of context. Psychol Med 2009;37:1413-1425.

12 Pickett KE, Wilkinson RG. People like us: ethnic density effects on health. Ethn Health 2008;13:321-334.

13 Driessen G, Gunther N, Van Os J. Shared social environment and psychiatric disorder: a multilevel analysis of individual and ecological effects. Soc Psychiatry Psychiatr Epidemiol, 1998;33:606612.

14 NISRA. Census 2011: Detailed characteristics for Northern Ireland on health, religion and national identity. Belfast: Northern Ireland Statistics \& Research Agency 2013.

15 Mulholland C, Boyle C, Huda U, Clarke L, Meenagh C, Dempster M. Exposure to the "Troubles" in Northern Ireland influences the clinical presentation of schizophrenia. Schizophr Res, 2008;102:278-282.

16 Muldoon OT, Trew K, Todd J, Rougier N, McLaughlin K. Religious and national identity after the Belfast Good Friday Agreement. Political Psychology, 2007;28:89-103.

17 Northern Ireland Human Rights Commission. Submission to the United Nations committee on the elimination of racial discrimination. Belfast: Northern Ireland Human Rights Commission 2011.

18 O'Reilly D, Rosato M. Religious affiliation and mortality in Northern Ireland: Beyond Catholic and Protestant. Soc Sci Med, 2008;66:1637-1645.

19 Shuttleworth IG, Lloyd CD, Martin DJ. Exploring the implications of changing census output geographies for the measurement of residential segregation: The example of Northern Ireland 1991-2001. Journal of the Royal Statistical Society, 2011;174:1-16.

20 Schmid K, Tausch N, Hewstone M, Hughes J, Cairns E. The effects of living in segregated vs. mixed areas in Northern Ireland: A simultaneous analysis of contact and threat effects in the context of micro-level neighbourhoods. International Journal of Conflict and Violence, 2008;2:56-71.

21 Byrne J, Gormley Heenan C, Robinson G. Attitude to peace walls. University of Ulster: Research Report to the Office of First Minister and Deputy First Minister 2012.

22 NISRA. Northern Ireland multiple deprivation measure 2010. Belfast: Northern Ireland Statistics \& Research Agency 2010.

23 NINIS. Census 2011: Ethnicity, identity, language and religion interactive content. Northern Ireland Neighbourhood Information System. Accessed from http://www.ninis2.nisra.gov.uk/InteractiveMaps/Census\%202011/Religion\%20or\%20Religio n\%20Brought\%20Up\%20In\%20KS212NI/atlas.html [10 April 2017]. 
24 Bosqui TJ, Hoy K, Shannon C. A systematic review and meta-analysis of the ethnic density effect in psychotic disorders. Soc Psychiatry Psychiatr Epidemiol, 2014;49:519-529.

25 Halpern D, Nazroo J. The ethnic density effect: results from a national community survey of England and Wales. Int J Soc Psychiatry 2000;46:34-46.

26 Bécares L, Shaw R, Nazroo J, Stafford M, Albor C, Atkin K, Kiernan K, Wilkinson R, Pickett K. Ethnic density effects on physical morbidity, mortality and health behaviours: A systematic review of the literature. Am J Public Health, 2012;102:33-66.

27 Bull P. Shifting patterns of social identity in Northern Ireland. The Psychologist, 2006;19:40-43.

28 Crighton E. Iver MAM. The evolution of protracted ethnic conflict: Group dominance and political underdevelopment in Northern Ireland and Lebanon. Comparative Politics, 1991;23:127142.

29 McGladdery G. Perceptions of 'Siege Mentality': Northern Irish Protestants and White South Africans in the new political dispensation. Irish Studies in International Affairs, 2002;13:87103.

30 Bhui K, Stansfeld S, Head J, Haines M, Hillier S, Taylor S, Viner R, Booy R.. Cultural identity, acculturation, and mental health among adolescents in east London's multiethnic community. J Epidemiol Community Health, 2005;59:296-302.

31 Gallagher E, Cairns E. National identity and in-group/out-group attitudes: Catholic and Protestant children in Northern Ireland. European Journal of Developmental Psychology, 2011;8: 58-73.

32 Shuttleworth IG, Lloyd CD. Are Northern Ireland's communities dividing? Evidence from geographically consistent Census of Population data, 1971 -2001. Environment and Planning, 2009;41:213-229.

33 Hargie O, Dickson D, Mallett J, Stringer, M. Communicating social identity: A Study of Catholics and Protestants in Northern Ireland. Communication Research, 2008;35:792-821.

34 Betancourt TS, Khan, KT. The mental health of children affected by armed conflict: Protective processes and pathways to resilience. Int Rev Psychiatry, 2009;20:317-328.

35 Haslam SA, Jetten J, Postmes T, Haslam, C. Social identity, health and well-being: An emerging agenda for applied psychology. Applied Psychology, 2009;58:1-23.

36 Musterd S, Galster G, Andersson R. Temporal dimensions and measurement of neighbourhood effects. Environment and Planning, 2012;44:605 - 627.

37 Mac Ginty R, Muldoon OT, Ferguson N. No war, no peace: Northern Ireland after the Agreement. Political Psychology, 2007;28:1-11. 
38 McDoom OS, Gisselquist RM. The measurement of ethnic and religious divisions: Spatial, temporal, and categorical dimensions with evidence from Mindanao, the Philippines. Social Indicators, 2016;129:863-891.

39 Lee D, Minton J, Pryce G. Religious segregation in Belfast: Detecting real change in patterns of population movement. Research Briefing, Applied Quantitative Methods Network. Accessed from https://www.aqmen.ac.uk/sites/default/files/BP\%208\%20V8.pdf [25 October 2015].

40 Paolini S, Hewstone M, Cairns E, Voici, A. Effects of direct and indirect cross-group friendships on judgments of Catholics and Protestants in Northern Ireland: The mediating role of an anxiety-reduction mechanism. Society for Personality and Social Psychology, 2004;30:770780. 